\title{
A young women with a large ovarian mass
}

\author{
Vicky O'Dwyer", Kevin Hickey
}

Midwestern Regional Hospital, Limerick, Ireland

Email: "vicky.odwyer@ucd.ie

Received 23 November 2012; revised 25 December 2012; accepted 4 January 2013

\begin{abstract}
A dermoid ovarian cyst is the commonest ovarian cyst in women of reproductive age. We report a young woman who presented with a large abdominal mass. We discuss the differential diagnosis and surgical management of a large complex ovarian mass in a young woman.
\end{abstract}

Keywords: Ovarian Cyst; Ovarian Cancer

\section{INTRODUCTION}

Ovarian cancer is the fifth commonest cancer among women and the most lethal gynaecological malignancy [1]. Due to vague symptoms in the early stages of disease it often presents late, with abdominal distension due to a large mass or ascites [2].

The differential diagnosis of an ovarian mass includes both benign and malignant disease. In young women with a large ovarian mass borderline or malignant disease of the ovary is an important differential to consider [3]. However, in young women smaller complex ovarian masses could be an endometrioma, a haemorrhagic cyst or a dermoid cyst. It is important to consider these causes when deciding on the appropriate surgical management.

\section{CASE REPORT}

A 37 year old lady attended the gynaecology outpatient clinic with a three month history of abdominal swelling. She was parous, with a regular 28 day menstrual cycle, and a normal cervical smear within the last year. There was no family history of breast or ovarian cancer.

On examination there was a mobile 26 week pregnancy size abdominal mass arising from the pelvis. Her CA125 was normal. An ultrasound scan demonstrated a large abdominal mass extending into the pelvis containing solid and cystic areas. This was thought to be an ovarian tumour. The uterus was normal and visualised separate from the mass. A CT was then performed which confirmed a large right ovarian mass that was solid and

*Corresponding author. cystic. There was no ascites or enlarged retroperitoneal lymph nodes, and no evidence of pleural effusion.

A midline laparotomy and right salpingo-oophrectomy was peformed. The operative findings were of a large complex right ovarian cyst with an intact capsule. The cyst had sebaceous material and hair content suggestive of dermoid aetiology. The uterus, left fallopian tube, peritoneal surfaces, omentum and liver all appeared healthy. The histology report confirmed a $23 \times 16 \times 14 \mathrm{~cm}$ smooth walled cyst, weighing $2.5 \mathrm{~kg}$. The cyst contained teeth, hair and sebaceous fluid. The peritoneal washings contained benign mesothelial cells.

\section{DISCUSSION}

A dermoid cyst is a benign cyst composed of tissue differentiated from three germ cell lines. It often presents with abdominal pain. Complications include torsion, and rupture causing chemical peritonitis.

Laparoscopic management has been shown to be associated with less bleeding and a shorter hospital stay than laparotomy in patients with a dermoid cyst measuring < $12 \mathrm{~cm}$ [4]. However, minilaparotomy has been shown to be a good surgical technique for removal of a dermoid cyst due to shorter operating time than laparoscopy, the possibility of removing the mass from the abdominal cavity without rupture and the possibility to preserve more ovarian tissue [5].

Spillage of dermoid cyst contents is more common when removal is performed laparoscopically than by laparotomy [6]. Case reports have described chemical peritonitis following intraperitoneal spillage of dermoid cyst contents causing pelvic adhesions, bowel obstruction, abdominal wall abscess, and enterocutaneous fistula formation [7].

Women presenting with a large complex ovarian cyst are often referred for extensive surgical staging to ensure the correct diagnosis and treatment of a possible epithelial ovarian cancer [8].

This case represents one of the largest dermoid cysts ever reported and shows that in young women with a large complex mass it must be considered among the 
differential diagnoses.

\section{REFERENCES}

[1] Kurman, R.J. and Shih, I.M. (2010) The origin and pathogenesis of epithelial ovarian cancer: A proposed unifying theory. The American Journal of Surgical Pathology, 3, 433-443. doi:10.1097/PAS.0b013e3181cf3d79

[2] Dodge, J.E., Covens, A.L., Lacchetti, C., Elit, L.M., Le, T., Devries-Aboud, M., et al. (2012) Management of a suspicious adnexal mas: Clinical practice guideline. Current Oncology, 4, 244-257.

[3] Carter, J., Pather, S., Abdel-Hadi, M., Nattress, K., Dalrymple, C. and Beale, P. (2006) Not all ovarian cysts in young woman are benign: A case series and review of the management of complex adnexal masses in young women. Australian and New Zealand Journal of Obstetrics and Gynaecology, 4, 350-355. doi:10.1111/j.1479-828X.2006.00605.X

[4] Briones-Landa, C.H., Ayala-Yáñez, R., Leroy-López, L., Anaya-Coeto, H., Santarosa-Pérez, M.A. and ReyesMuñoz, E. (2010) Comparison of laparoscopic vs. lapa- rotomy treatment in ovarian teratomas. Ginecología y Obstetricia de México, 10, 527-532.

[5] Bolla, D., Deseö, N., Sturm, A., Schöning, A. and Leimgruber, C. (2012) Minilaparotomy a good option in specific cases: A case report of bilateral ovarian germ cell tumor. Case Reports in Obstetrics and Gynecology, 2012, Article ID: 589568.

[6] Laberge, P. and Levesque, S. (2006) Short-term morbidity and long-term recurrence rate of ovarian dermoid cysts treated by laparoscopy versus laparotomy. Journal of Obstetrics and Gynaecology in Canada, 9, 789-793.

[7] Shamshirsaz, A.A., Amirhoushang, A.A., Shamshirsaz, A., Vibhakar, J.L., Broadwell, C. and Van Voorhis, B.J. (2011) Laparoscopic management of chemical peritonitis caused by dermoid cyst spillage. Journal of the Society of Laparoendoscopic Surgeons, 15, 403-405.

[8] Partheen, K., Kristjansdottir, B. and Sundfeldt, K. (2011) Evaluation of ovarian cancer biomarkers HE4 and CA125 in women presenting with a suspicious cystic ovarian mass. Journal of Gynecologic Oncology, 4, 244-252. doi:10.3802/jgo.2011.22.4.244 